\title{
Mapping Global GDP Exposure to Drought
}

\author{
Fubao Sun, Tingting Wang, and Hong Wang
}

\section{Introduction}

Accumulative evidences have shown that anthropogenic climatic changes are already influencing the frequency, magnitude, and duration of droughts (Mann and Gleick 2015). Severe drought events during the past decades, e.g., the East Africa drought, the California drought, and a series of severe drought events recently in southern China have profound impacts on global and regional water resources, agriculture activities, and the ecosystem (Wada et al. 2013), and have resulted in huge losses to the society. The climate warming has intensified the magnitude and severity of drought conditions, posing considerable economic, societal, and environmental challenges globally (Carrão et al. 2016; $\mathrm{Su}$ et al. 2018; Ahmadalipour et al. 2019; Gu et al. 2020; Cook et al. 2020). Drought losses have significantly increased in recent years, for a range of reasons, including nonclimatic factors around the world. Enhanced drying has been observed and projected over many land areas under a

Authors: Fubao Sun, Tingting Wang, Hong Wang.

Map Designers: Qingyuan Ma, Jing'ai Wang, Ying Wang.

Language Editor: Tingting Wang.

F. Sun $(\bowtie) \cdot$ T. Wang $\cdot$ H. Wang

Key Laboratory of Water Cycle and Related Land Surface Processes, Institute of Geographic Sciences and Natural Resources Research, Chinese Academy of Sciences, Beijing, 100101, China e-mail:sunfb@igsnrr.ac.cn

\section{F. Sun}

State Key Laboratory of Desert and Oasis Ecology, Xinjiang Institute of Ecology and Geography, Chinese Academy of Sciences, Urumqi, 830011, China

Akesu National Station of Observation and Research for Oasis Agro-ecosystem, Akesu, 843000, China

College of Resources and Environment, University of Chinese Academy of Sciences, Beijing, 100049, China warming climate, due to increasing atmospheric concentrations of greenhouse gases. In the context of climate change, drought exposure is likely to increase in many historically drought-prone regions (Dai 2011; Liu et al. 2020; Su et al. 2018). A better understanding of changes in global drought characteristics and their socioeconomic impacts in the twenty-first century should feed into long-term climate adaptation and mitigation plans.

With expected increases in widespread severe drought events and rapid socioeconomic development, more GDP will be exposed to droughts, resulting in higher drought risks and more potential GDP losses in the future. Exposure of socioeconomic activities is one of the most important aspects of drought risk assessment ( $\mathrm{Su}$ et al. 2018). The changing vulnerability, exposure of socioeconomic activities to climate extremes are driving a need to move beyond administrative unit-based analyses to enable flexible integration with spatially explicit datasets of population and economic systems of long-term SSPs (Jones et al. 2015; Chen et al. 2017; Su et al. 2018; Liu et al. 2018; Liu et al. 2020). Yet, the existing analyses are very limited and mainly focused on the population exposure to droughts, and the magnitude of drought impacts on GDP in a warming climate is poorly addressed across the globe.

Hence, the GDP exposure to droughts, especially to severe and extreme droughts, across the globe from baseline period (1986-2005) and future scenarios (2016-2035 and 20462065) was estimated and quantified based on the general circulation models (GCMs) from the Institute of Atmospheric Physics, Chinese Academy of Sciences, and the GDP data from the Institute of Geographic Sciences and Natural 
Fig. 1 Global GDP exposure to droughts for the historical period and the 2030s and 2050s under SSP1 -3 , and RCP2.6, RCP4.5, and RCP8.5 scenarios

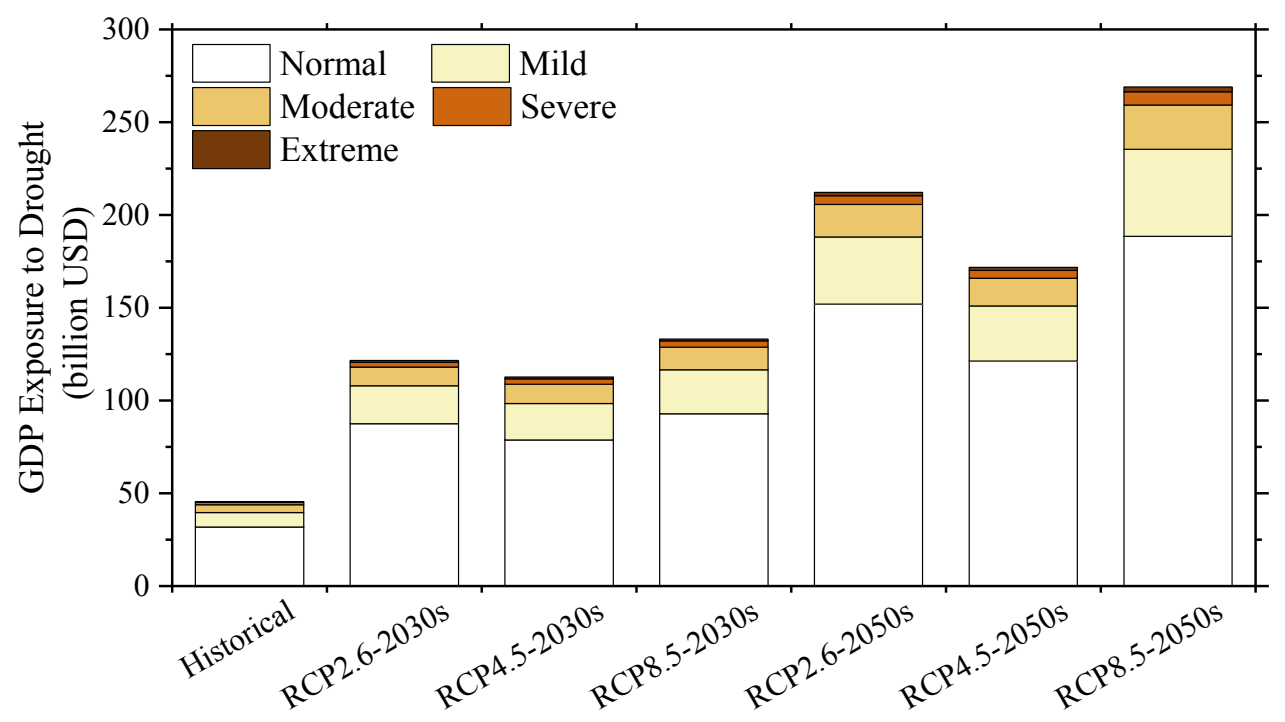

Resources Research of the Chinese Academy of Sciences. The GDP exposure to droughts is mapped at the grid level.

\section{Method}

\subsection{Drought Estimation}

The Palmer Drought Severity Index (PDSI) is a simple water balance model originally designed by Palmer under the framework of water balance between water supply and atmospheric evaporative demand (Palmer 1965), and is estimated by the difference between monthly precipitation, potential evaporation, and some other parameters. There were 13 out of 21 GCMs in CMIP5 (Coupled Model Intercomparison Project phase 5): CanESM2, CNRM-CM5, CSIRO-Mk3-6-0, GFDL-CM3, GFDL-ESM2M, IPSL-CM5A-MR, MIROC5, MIROC-ESM, MIROC-ESM-CHEM, MPI-ESM-LR, and MPI-ESM-MR under each of three Representative Concentration Pathway (RCP) scenarios, i.e., RCP2.6, RCP4.5 and RCP8.5, collected and used here.

The precipitation, maximum temperature, and minimum temperature from above GCMs for both historical period (1986-2005) and future of the 2030s (2016-2035) and the 2050s (2046-2065) under the RCP 2.6, RCP4.5, and RCP8.5 scenarios were obtained for PDSI calculation. The degrees of droughts are identified by PDSI values below a threshold value (PDSI $<-1$ ): PDSI $\geq-1$ represents normal conditions, PDSI in the range of $[-2,-1)$ as mild drought, $[-3,-2)$ as moderate drought, $[-4,-3)$ as severe drought, and PDSI $<-4$ as extreme drought. Drought frequency is the times of each classification per grid cell in the selected 20-year period for all GCMs.

\subsection{GDP Exposure to Droughts}

The GDP exposure to varying degrees of droughts is defined as the GDP that is exposed to normal conditions, mild, moderate, severe, and extreme droughts, i.e., the frequency of each class multiplied by the GDP values exposed per grid cell for both the historical period and the future periods under the three RCP and SSP scenarios. For example, the global GDP in 2030 of SSP1 was multiplied by normal condition, mild, moderate, severe, and extreme drought frequencies per grid cell, respectively, under the RCP2.6 scenario to estimate the corresponding GDP exposure to each degree of drought in the 2030s at a spatial resolution of 0.25 degrees. The ensemble mean of GDP exposure of all GCMs was adopted in our analysis.

The unit of GDP exposure to droughts is purchasing power parity (PPP) in 2005 USD, which ensures spatiotemporal comparisons of substantial long-term changes of climate and economic activities for both the historical period and the future projections under different climate change and socioeconomic scenarios.

\section{Results}

The global GDP exposure to normal (no drought), mild, moderate, severe, and extreme droughts is shown in Fig. 1, and the proportions of GDP exposure to severe and extreme droughts by gross national income (GNI) per capita at 2019 level provided from the World Bank high-income countries ( $\geq 52,412$ GNI per capita), upper middle income countries ( $\leq 17,196$ GNI per capita), middle income countries $(\leq 11,934$ GNI per capita), low and middle income 
countries $(\leq 10,937$ GNI per capita), lower middle income countries ( $\leq 6761$ GNI per capita), and low income countries ( $\leq 2458$ GNI per capita) are shown in Fig. 2.

There is about $70 \%$ of global GDP exposed to normal conditions and less than $5 \%$ exposed to severe and extreme droughts for the historical period and the 2030s and the 2050s under SSP1-3 and RCP2.6, RCP4.5, and RCP8.5 scenarios. The global GDP exposure to severe droughts will be as high as about 2.8 -3.6 billion USD, and the GDP exposure to extreme droughts will be about $0.5-1.1$ billion in the 2030s for SSP1-3, respectively. Furthermore, the GDP exposure to severe and extreme droughts increases in the 2050 s, with exposure of 1.5 to 2.1 times for severe droughts and 1.7 to 2.3 times for extreme droughts for SSP1 -3 compared to their 2030s values (Fig. 1).

The GDP exposure to severe and extreme droughts depicts major differences around the globe (Fig. 2). The statistics show that the GDP exposure to droughts is the highest in upper middle income countries but the lowest in low income, lower middle income, and low and middle income countries.

(a)

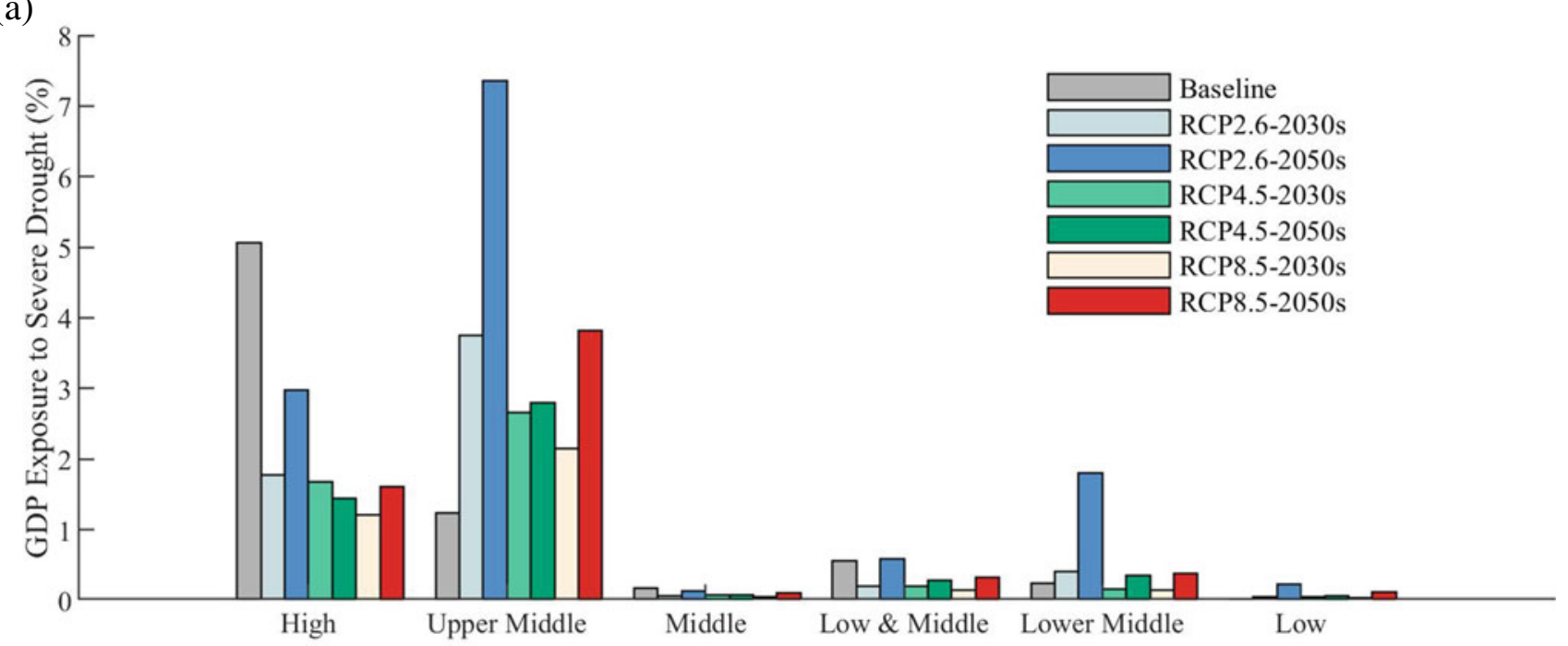

(b)

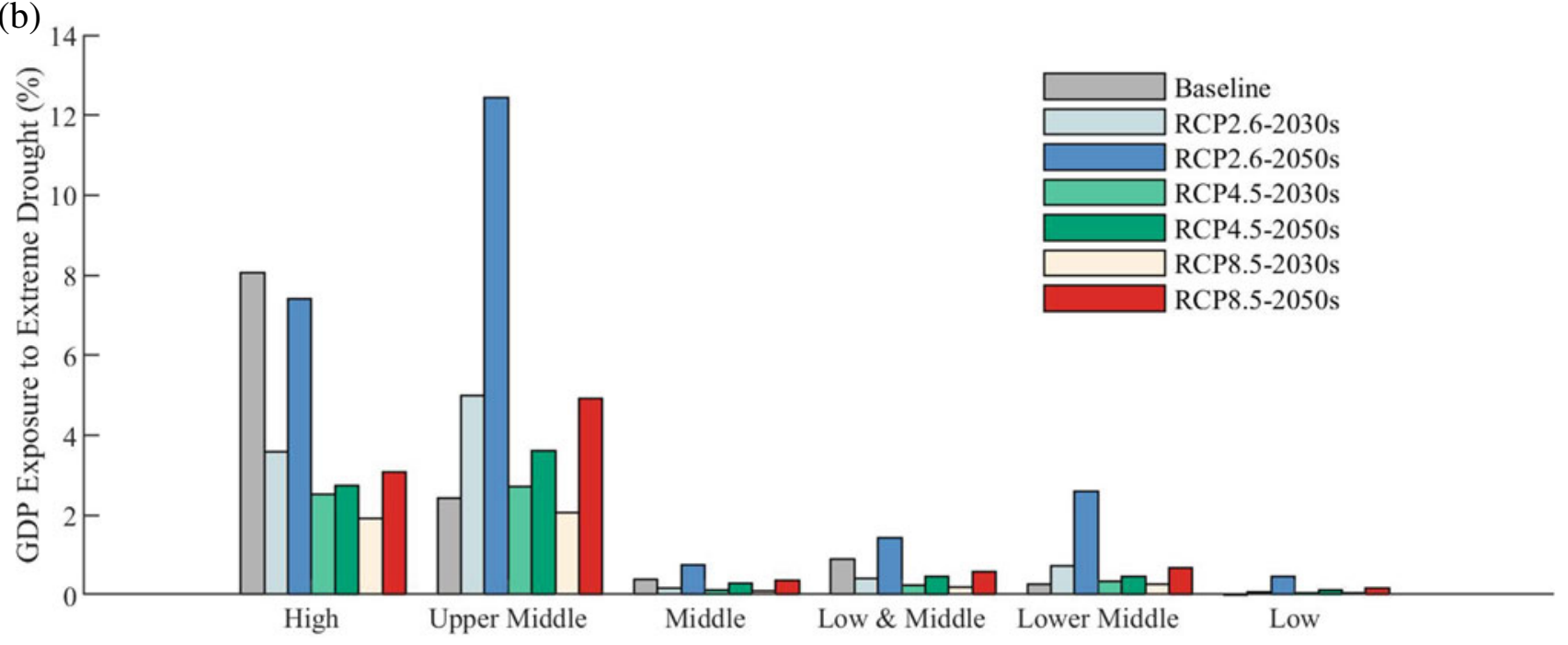

Fig. 2 Global GDP exposure (\%) to severe droughts (a) and extreme droughts (b) by gross national income (GNI) for the historical period and the 2030s and 2050s under SSP1-3 and RCP2.6, RCP4.5, and RCP8.5 scenarios 


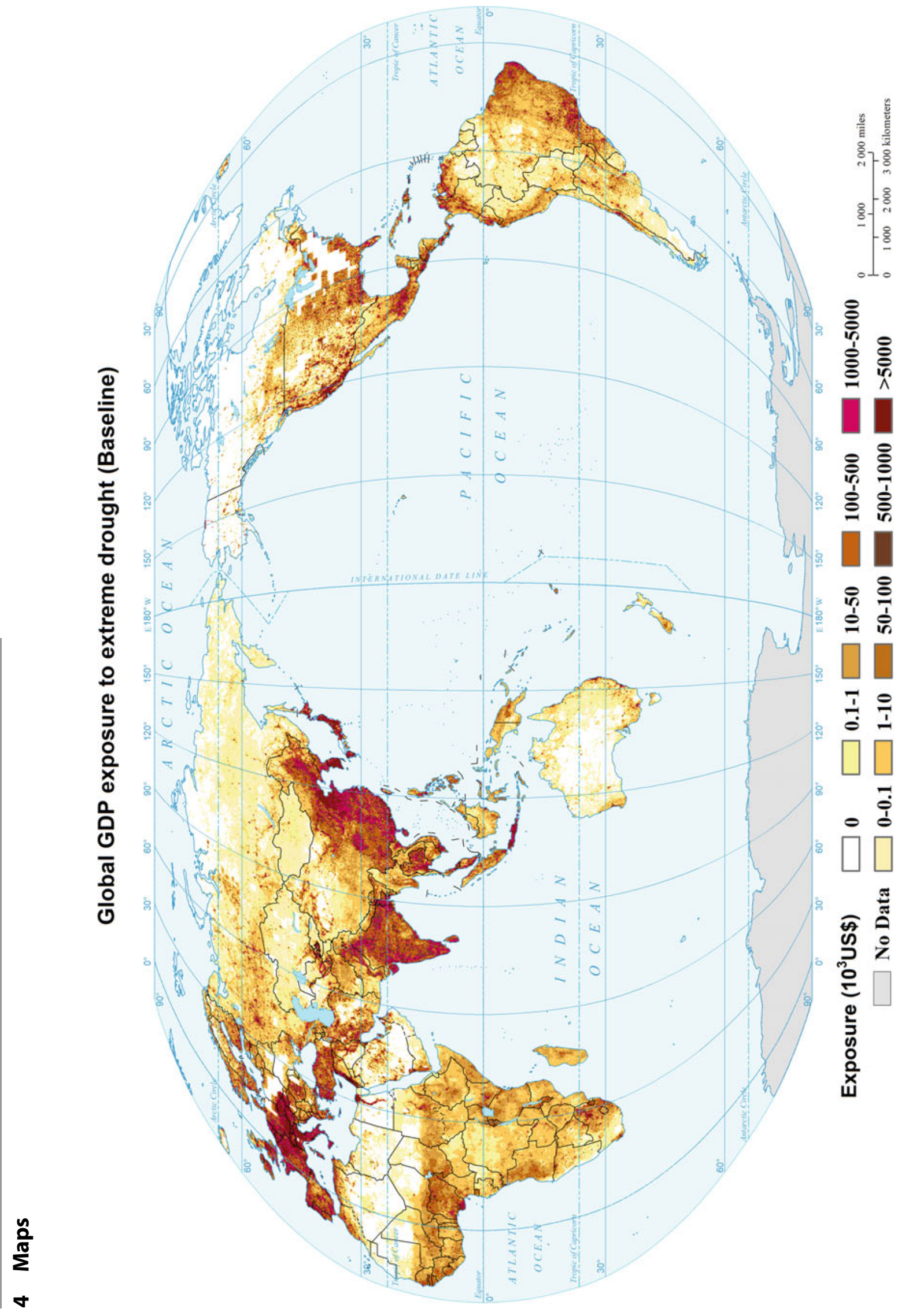


Global GDP exposure to extreme drought (2030s, RCP2.6-SSP1)

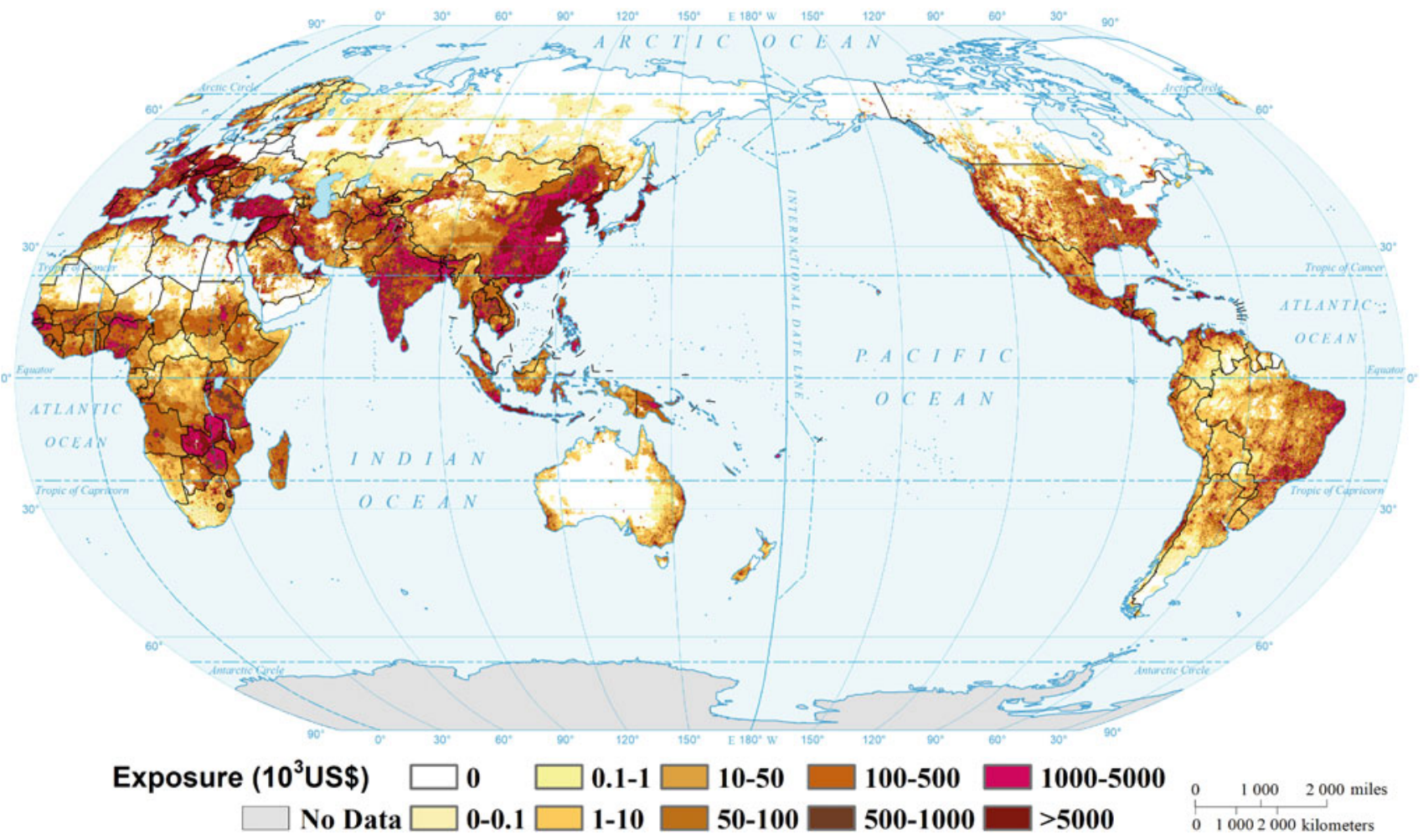

Global GDP exposure to extreme drought (2030s, RCP4.5-SSP2)

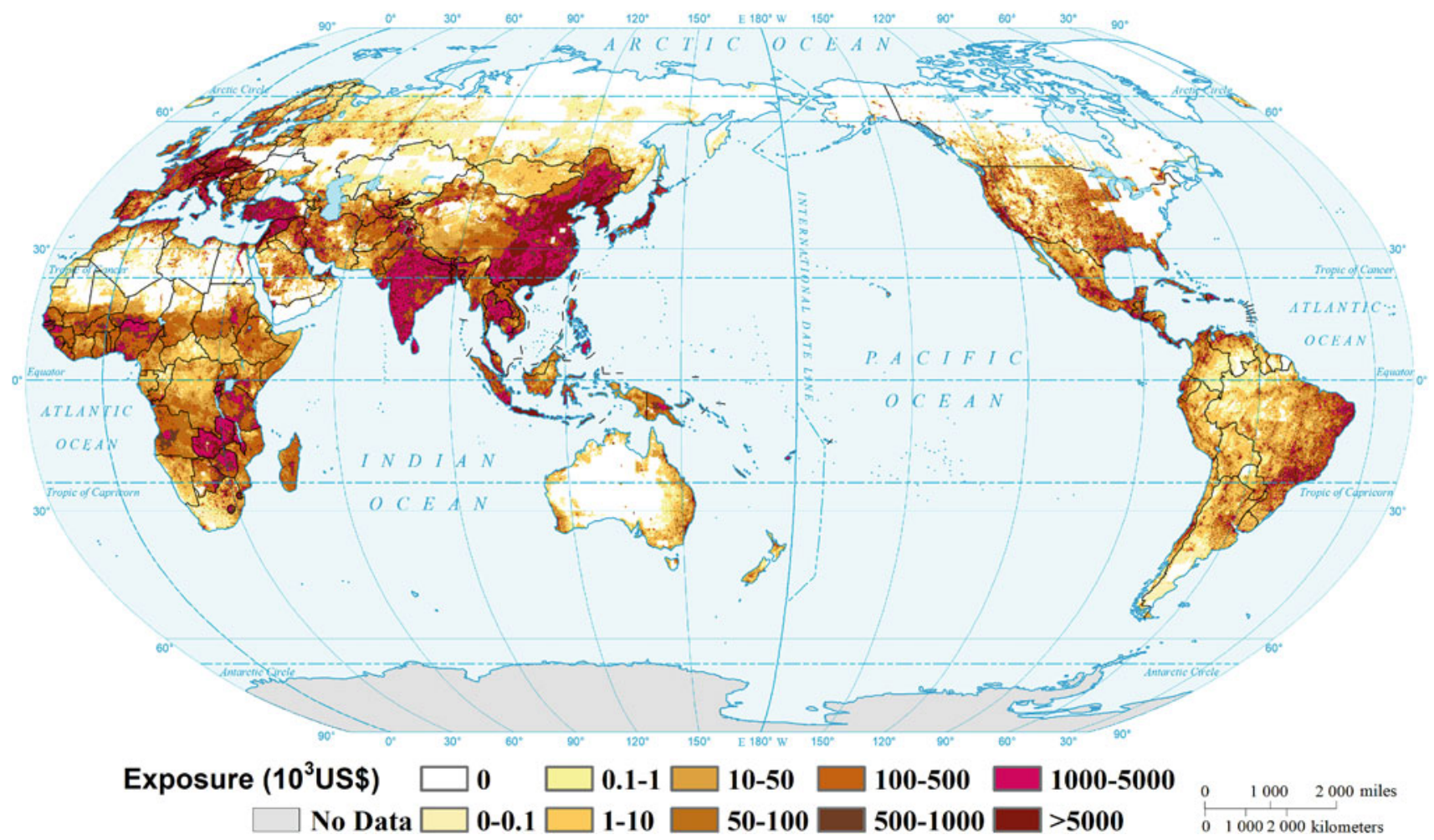




\section{Global GDP exposure to extreme drought (2030s, RCP8.5-SSP3)}

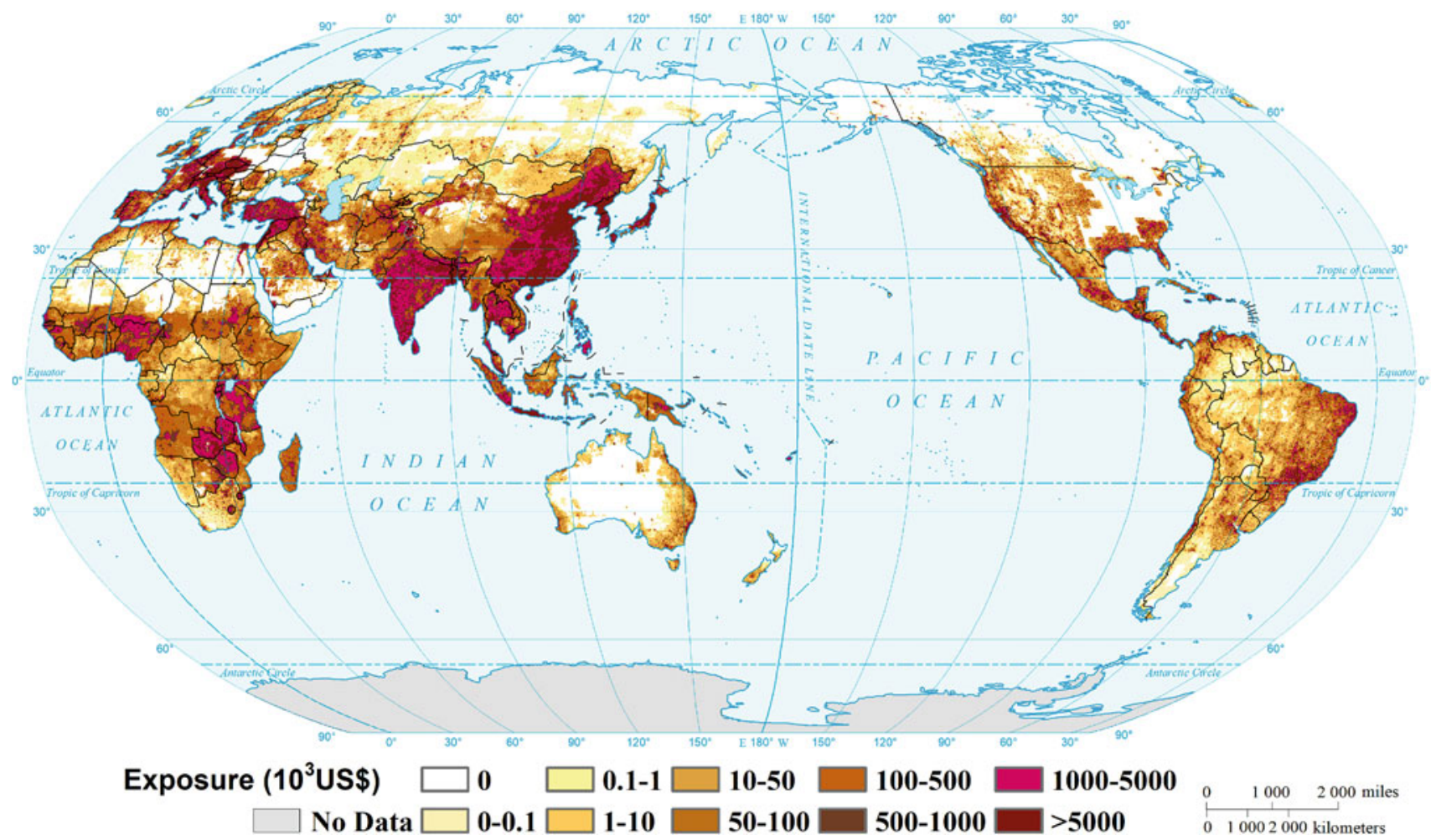

Global GDP exposure to extreme drought (2050s, RCP2.6-SSP1)

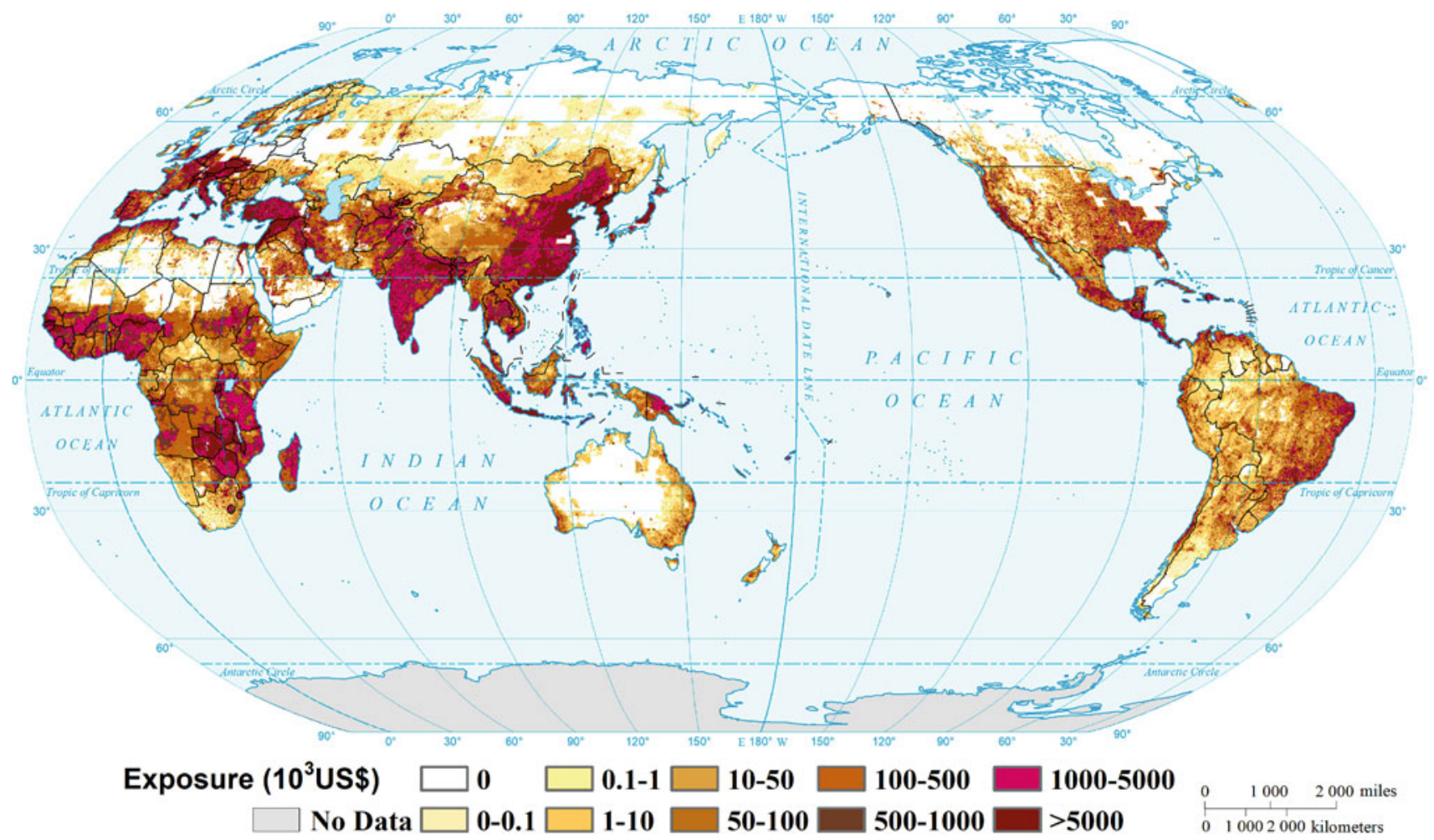


Global GDP exposure to extreme drought (2050s, RCP4.5-SSP2)

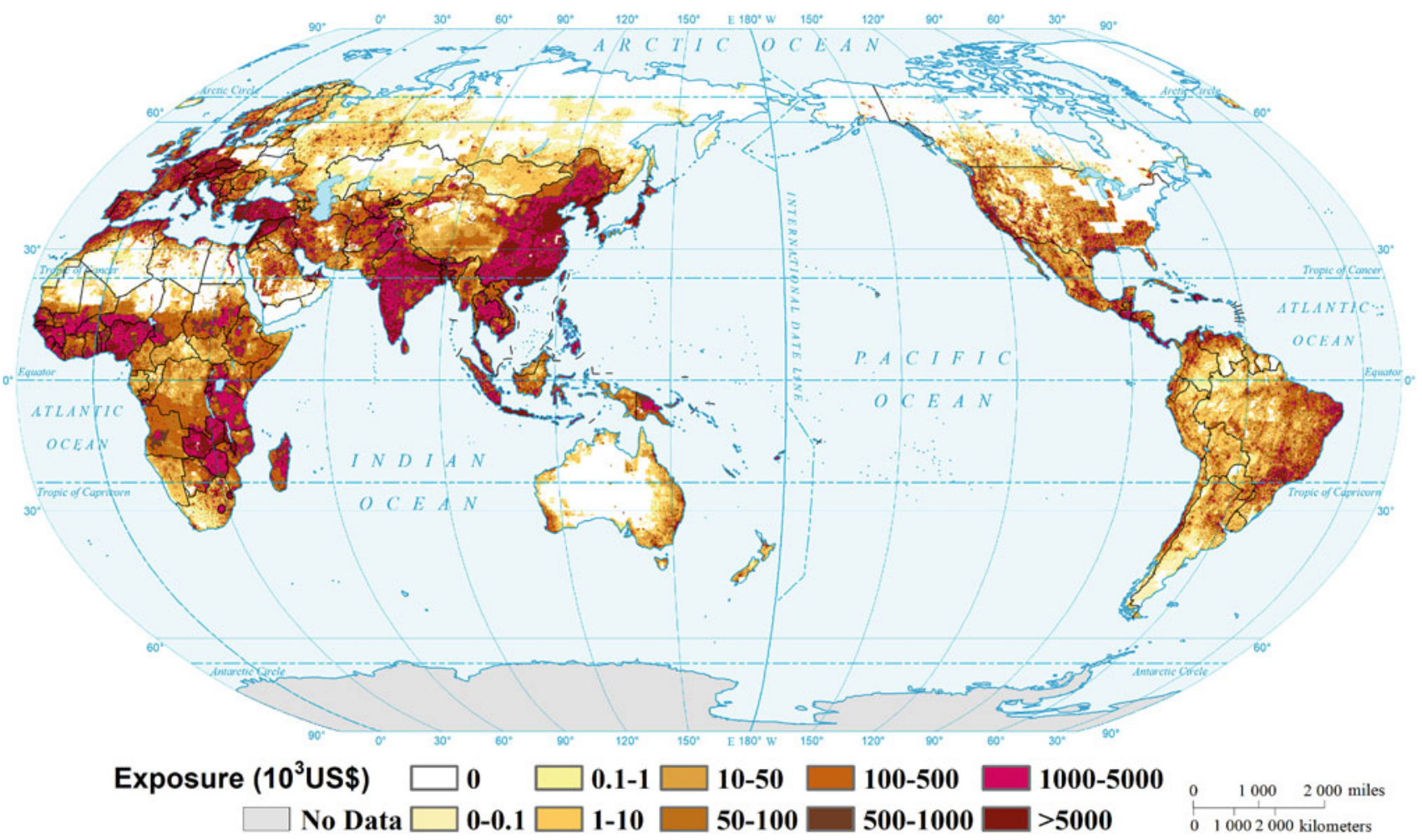

Global GDP exposure to extreme drought (2050s, RCP8.5-SSP3)

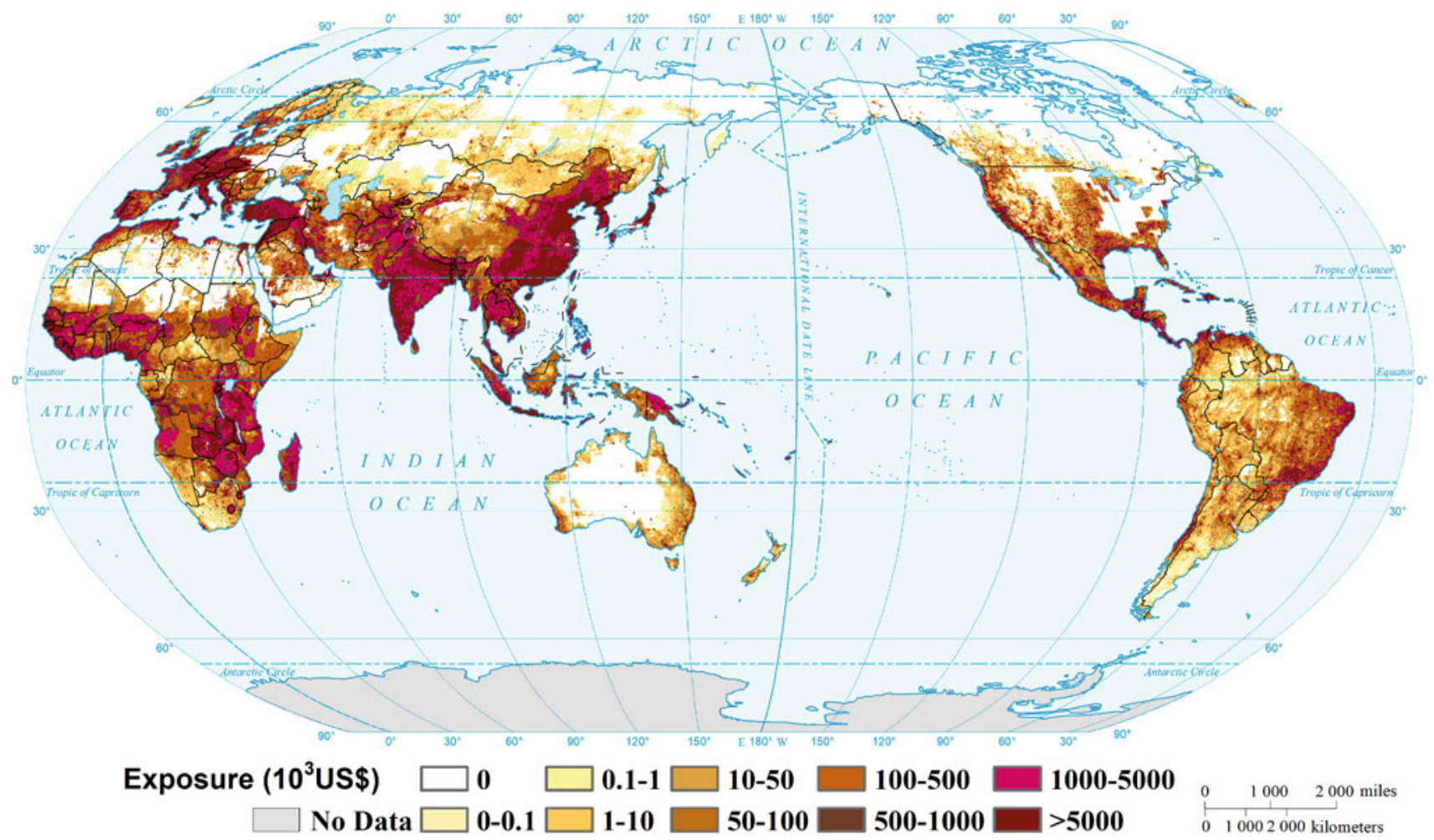




\section{References}

Ahmadalipour, A., H. Moradkhani, A. Castelletti, and N. Magliocca. 2019. Future drought risk in Africa: Integrating vulnerability, climate change, and population growth. Science of the Total Environment 662: 672-686.

Carrão, H., G. Naumann, and P. Barbosa. 2016. Mapping global patterns of drought risk: An empirical framework based on sub-national estimates of hazard, exposure and vulnerability. Global Environmental Change 39: 108-124.

Chen, J., Y. Liu, T. Pan, Y. Liu, F. Sun, and Q. Ge. 2017. Population exposure to droughts in China under $1.5^{\circ} \mathrm{C}$ global warming target. Earth System Dynamics 9: 1-13.

Cook, B., J. Mankin, K. Marvel, A. Williams, J. Smerdon, and K. Anchukaitis, 2020. Twenty-first century drought projections in the CMIP6 forcing scenarios. Earth's Future 8(6): e2019EF001461.

Dai, A. 2011. Drought under global warming: A review. Wiley Interdisciplinary Reviews: Climate Change 2: 45-65.

Gu, L., J. Chen, J. Yin, S.C. Sullivan, H.M. Wang, S. Guo, L. Zhang, and J.S. Kim. 2020. Projected increases in magnitude and socioeconomic exposure of global droughts in 1.5 and $2{ }^{\circ} \mathrm{C}$ warmer climates. Hydrology and Earth System Sciences 24(1): 451-472.
Jones, B., B.C. O’Neill, L. Mcdaniel, S. Mcginnis, L.O. Mearns, and C. Tebaldi. 2015. Future population exposure to US heat extremes. Nature Climate Change 5: 592-597.

Liu, W., F. Sun, W.H. Lim, J. Zhang, H. Wang, H. Shiogama, and Y. Zhang. 2018. Global drought and severe drought-affected populations in 1.5 and $2{ }^{\circ} \mathrm{C}$ warmer worlds. Earth System Dynamics 9(1): 267-283.

Liu, Y., J. Chen, T. Pan, Y. Liu, Y. Zhang, Q. Ge, P. Ciais, and J. Penuelas. 2020. Global socioeconomic risk of precipitation extremes under climate change. Earth's future 8(9): e2019EF001331.

Mann, M.E., and P.H. Gleick. 2015. Climate change and California drought in the 21st century. Proceedings of the National Academy of Sciences 112 (13): 3858-3859.

Palmer, W. 1965. Meteorological droughts. US Department of Commerce Weather Bureau Research Paper 45, 58.

Su, B., J. Huang, T. Fischer, Y. Wang, Z.W. Kundzewicz, J. Zhai, H. Sun, A. Wang, et al. 2018. Drought losses in China might double between the $1.5 \mathrm{C}$ and $2.0 \mathrm{C}$ warming. Proceedings of the National Academy of Sciences 115: 10600-10605.

Wada, Y., L.P. Van Beek, N. Wanders, and M.F. Bierkens. 2013. Human water consumption intensifies hydrological drought worldwide. Environmental Research Letters 8(3): 034036.
Open Access This chapter is licensed under the terms of the Creative Commons Attribution 4.0 International License (http:// creativecommons.org/licenses/by/4.0/), which permits use, sharing, adaptation, distribution and reproduction in any medium or format, as long as you give appropriate credit to the original author(s) and the source, provide a link to the Creative Commons license and indicate if changes were made.
The images or other third party material in this chapter are included in the chapter's Creative Commons license, unless indicated otherwise in a credit line to the material. If material is not included in the chapter's Creative Commons license and your intended use is not permitted by statutory regulation or exceeds the permitted use, you will need to obtain permission directly from the copyright holder. 